\title{
Ageing more gracefully
}

\section{Linda Geddes is moved by an insider's take on how doctors and geriatric-care systems are failing old people and the dying.}

A tul Gawande's Being Mortal left me tearful, angry and unable to stop talking about it for a week. Gawande's central argument is this: since the mid-twentieth century, death has been progressively transformed into a medical experience that the majority of doctors are ill-equipped to deal with. The evidence shows that this giant experiment is failing. As Gawande notes, when the medical problems of the dying cannot be fixed by medicine, "callousness, inhumanity, and extraordinary suffering" can result.

This book is a call to action - a reconsideration of what makes life worth living and how all, including elderly people and those with terminal illnesses, can find access to that. Making old age meaningful, Gawande shows, demands a massive shake-up in medical and nursing care. With the number of over-65s in the United States and Europe expected to double by 2050 , this is a time bomb that we need to defuse fast.

When I discussed the book with a junior-doctor friend, he related an episode from a night shift. A terminally ill patient's breathing had dropped to three breaths per minute - possibly as a result of morphine given for pain relief. The choice was stark: administer a drug to reverse the morphine, even though the patient's brain was probably irreversibly damaged from low oxygen intake, or leave the man (who had asked not to be resuscitated) to die. My friend's supervisor stepped in and reversed the morphine; the man ultimately died soon afterwards anyway.

Being Mortal is filled with case studies similar to this. The lives and deaths of various members of Gawande's own family provide the book's overarching narrative. Gawande describes his father's struggle with cancer of the spinal cord and brainstem, for instance, and how Gawande senior opted for surgery to reduce the size of the tumour, avoiding chemotherapy to preserve his mental clarity. But this is no voyeuristic tour. A surgeon himself, Gawande is eloquent about the inadequacy of medical school in preparing doctors to confront the subject of death with their patients. He admits to having skirted around the issue himself, offering invasive medical procedures with little chance of benefit to make the patient feel that he is

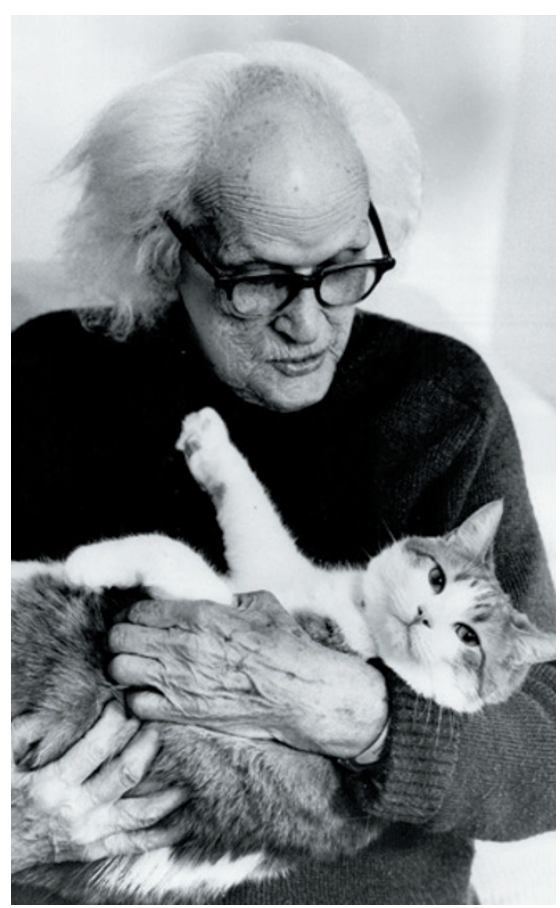

Caring for animals can boost cardiovascular health in elderly people.

\section{doing something.}

As well as discussing realities for people with terminal illnesses, Gawande dwells on ageing, revealing that many doctors dislike caring for elderly people with multiple health issues, and often find it overwhelming. Geriatricians, he suggests, can offer key lessons to other medics about listening, prioritizing and intervening to enable elderly people to maintain independence, often through simple interventions such as foot care to reduce chances of falling.

Gawande often forces readers to reflect on the issues ourselves. He sets us up to ask our own questions about common dilemmas such as putting frail elderly relatives into anonymous facilities - before offering answers pages later. Apropos of that vexed phenomenon, among others, he also

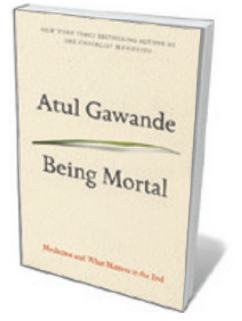

Being Mortal: Medicine and What Matters in the End ATUL GAWANDE Metropolitan/Profile: 2014. offers historical context. Nursing homes, he shows, originated in the United States in the 1950s to ease pressure on hospital beds by providing care for recovering patients. They were not designed as a longterm solution for elderly people.

Gawande challenges the idea that the standard US or UK care-home model is the only available choice. He describes the Chase Memorial Nursing Home in New Berlin, New York, which in 1991 brought in 2 dogs, 4 cats, 100 parakeets, a colony of rabbits and a flock of hens, and encouraged residents to care for them. It also established a flower and vegetable garden and on-site childcare for staff. Pet care, gardening and social interaction with the young offer significant benefits, Gawande suggests: within two years, the number of prescriptions per resident fell to half that of a control home nearby. Other studies suggest that pet ownership confers better cardiovascular health and boosts social interaction, for example. Gawande also describes a low-income apartment complex, Peter Sanborn Place in Reading, Massachusetts, where aides, physical therapists and visiting nurses help the ageing residents to assist with laundry, shopping and cleaning.

One criticism I have of the book is that Gawande does not really touch on how such innovative communities could be funded on a larger scale, or discuss the economics of nursing care. Peter Sanborn Place, for instance, gets some state funding but relies mostly on charitable donations. Nor does the book address issues of neglect in nursing homes, or the deliberate abuse of vulnerable residents. A 2012 congressional study found reports of serious physical, sexual or verbal abuse at one in three nursing homes in the United States.

Even so, it is rare to read a book that sparks so much hard thinking. In my case, it has opened the door to discussions with close relatives about how they wish to spend their final days - conversations that we should surely all be having, however difficult they are to start..

Linda Geddes is a freelance science writer in Bristol, UK, and a consultant to New Scientist magazine. e-mail:lindaged@yahoo.com 